\title{
Group physiotherapy with survivors of torture in urban and camp settings in Jordan and Kenya
}

\author{
Laura Pizer Gueron, PT, MPH, DPT1', Arobogust Amoyi, PT², Winnie Chao, PT $^{3}$, \\ Justine Chepngetich, $\mathrm{PT}^{4}$, Jepkemoi Joanne Kibet, PT, MS, doctoral candidate ${ }^{5}$, \\ Stephen Nyambok, PT $^{6}$ and Joseph Wesonga, PT, MPH7
}

\section{Key points of interest}

- Provisional results in a group physiotherapy model suggest clinically and statistically significant improvement in pain, mobility and sleep.

- Improvements noted were similar between survivors of torture (SOT) and non- SOT.

\section{Abstract}

Introduction: The Center for Victims of Torture has developed an interdisciplinary group treatment. The program is supported by a clinical assessment that records a broad set of indicators of participant experience and functioning.

Methods: Survivors are identified through referral systems, community education and sensitization campaigns, contacts and trainings with other NGOs and health care providers. Following an informed consent process, survivors participate in a comprehensive individual assessment and then progress to a 10-week

1) Clinical Advisor for Physiotherapy, Kenya programs, CVT.

Correspondence to: lgueron@cvt.org

2) Physiotherapist, CVT- Nairobi

3) Physiotherapist, CVT -Kakuma

program. Wherever possible, follow-up assessments are conducted 2 weeks after the sessions end, and at 3, and 9 months following completion.

Results: On average, participants who completed 3-month follow-up assessments showed statistically and clinically significant improvements.

Discussion: Provisional results are encouraging. As nearly all participants receive both counseling and physiotherapy (PS), it is difficult to know which benefits can be attributed to PS alone.

Keywords: group PS, interdisciplinary care, refugee, pain, pelvic floor.

\section{Introduction}

Many survivors of torture suffer from a wide range of physical and psychological symptoms and conditions (Crosby, 2013) which may benefit from PS intervention. These include: traumatic brain injuries, nerve injuries, injury to various parts of the body from beatings including those to the feet; burns; damage to the pelvic floor from sexual torture; fractures

4) Physiotherapist, CVT -Kakuma

5) Physiotherapy Trainer, CVT-Nairobi. Correspondence to: jkibet@cvt.org

6) Physiotherapist, CVT-Nairobi

6) Physiotherapy Trainer, CVT-Kakuma. Correspondence to: jwesonga@cvt.org 
and amputations (Amris et al., 2019; Prip et al., 2016). Further, many survivors of torture have issues with chronic pain, even years following their torture experiences (Harlacher et al., 2019; Kaur et al., 2020; Wang et al., 2016; Williams \& Baird, 2016).

Survivors who have experienced torture and other forms of trauma also often experience: decreased body awareness (numbing of sensations and difficulty identifying sensations, decreased flow and vitality of movement), self-regulation problems (unable to control bodily symptoms of emotional distress), anxiety (shortness of breath, muscle tension, headaches), depression (fatigue, joint pain, headaches, gastrointestinal disturbances, chronic pain) and cardiorespiratory symptoms such as heart racing, shortness of breath, chest heaviness, difficulty breathing, as well as sleep issues (Sandahl et al., 2017; Stammel et al., 2017).

\section{Chronic pain in survivors of torture}

Many survivors have issues with chronic pain, even years after they have experienced torture (Amris et al., 2019). The location of pain is at times correlated with the type and location of torture, such as having foot pain after sustaining falanga torture (Prip et al., 2016), head pain after traumatic brain injury, shoulder pain following suspension, and pelvic and back pain following sexual torture (Amris et al., 2019; Baird et al., 2017; Kaur et al., 2020; Nordin \& Perrin, 2019; Olsen et al., 2007; Tsur et al., 2020; Wang et al., 2016; Williams \& Baird, 2016). .

There is an expanding body of evidence showing that pain neuroscience education results in diminishment of pain and improved function. These interventions are typically paired with goal setting, instruction in ways to improve sleep, as well as in instruction in safe progression of exercises and functional mobil- ity, as part of a biopsychosocial approach to PS (Sallinen, 2018). No matter the type of pain (nocioceptive-from damage or potential damage to body, neuropathic - from damage to somatosensory nervous system or psychosomatic) skilled PS instruction often yields clinically meaningful improvement in pain (Harlacher et al., 2019; Louw et al., 2016; Wang et al., 2016; Wood \& Hendrick, 2019). It is also essential that physiotherapists (PTs) present information about pain in reassuring yet accurate ways, so as to enhance placebo effects and to minimize nocebo effects (Rossettini et al., 2020).

\section{Sleep deficits}

Deficits of sleep are commonly found among both those experiencing chronic pain and post-traumatic stress disorder (PTSD). The resulting insufficient sleep often leads to maintenance of pain, and decreased mood and energy level (Andrews et al., 2014). PS-led education often produces subjective improvements in patients' sleep duration and quality. The PTs typically instruct in relaxation techniques, mind-body connections, sleep positions and use of props such as pillows to decrease pain, and even in ideal timing of exercise and intake of food and beverages, in order to help patients to improve sleep (Nielsen, 2014; Sandahl et al., 2017; Siengsukon et al., 2017).

\section{Pelvic floor considerations}

PTs instruct patients in pelvic floor-related programming in both group and individual sessions in matters such as: ways to prevent urinary and fecal incontinence, constipation, painful sexual activity and other related topics. There is evidence to show that participating in either group or individual PS with pelvic floor emphasis can lead to meaningful improvements (Rosenberg, 2007). 


\section{Interdisciplinary needs}

Survivors of torture (SoT) typically have complex needs. There is evidence to support the need for PTs and other members of the team working with SoT and other forms of trauma to teach survivors about mind-body connections, including the role of breath, relaxation and practices of mindfulness (Gard \& Gyllensten, 2018; Van Damme, 2018). It has been proposed that patients be allowed opportunities to practice these approaches (Andersen et al., 2020; Buczynski et al., 2018; Nordbrandt et al., 2020; O’Sullivan, 2015; Persson et al., 2008; Price \& Hooven, 2018). Because of these complex needs and frequent co-morbidities, many have argued that an interdisciplinary approach to treatment, including PS and counseling, is ideal (de Ruiter et al., 2018; Stammel et al., Wang et al., 2016).

Individuals with chronic pain from a variety of causes often benefit from a multidisciplinary treatment approach as well (Saragiotto et al., 2016).

\section{Interoceptive awareness training}

PTs should create opportunities for survivors to increase their interoceptive awareness, which is the ability to identify, understand, and respond to signals of the body appropriately (Buczynski et al., 2018; de Ruiter et al., 2017; Price \& Hooven, 2018). The survivors should have exposure to sensations, such as faster breathing and heart rates, in a safe and supportive environment, where their fears and concerns are normalized and addressed. Care is taken to gradually progress the intensity of exercises to tolerance and to have these activities be enjoyable. By learning to focus attention inside of the body, such as to be able to soften areas of muscular tension, survivors can learn to have more control over their bodies (Price \& Hooven, 2018; Walker \& Shepherd, 2001).

\section{Self-sufficiency in survivors of torture}

Vancampfort and Stubbs (2018) emphasize that when working with survivors of trauma, and with patients who have chronic pain, it is essential that PTs guard against fostering excessive dependence on the PT. It is crucial that survivors learn skills that they can utilize cany time that they experience pain (Gard \& Gyllensten, 2018; Jones \& Kulnik, 2018). PTs need to focus on empowering SoT to learn strategies of pain reduction, exercise, improved posture and body mechanics, as well as to restore body awareness and to control their most disturbing symptoms. SoT should be empowered to be as independent as possible and to have knowledge about the role of exercise, pain management, body-mind connections and other concepts which are presented during PS sessions (Nielsen, 2014; O'Sullivan, 2015; Amris et al., 2019). It is important that patients also learn about the role of aerobic exercise in improving mood and on helping to decrease depressive symptoms as well. PTs have an important role in helping patients to find enjoyable ways to exercise safely (Knapen et al., 2018).

\section{Rationale for group model development}

Group PS is as effective as individual PS, for both those with mental health (Skjaerven et al., 2018) and physical health concerns (Andersen et al., 2019; O'Keeffe et al., 2017). There are few studies that demonstrate the efficacy of group PS for survivors of torture (Harlacher et al., 2019; Nordbrandt et al., 2020).

In a study, where survivors were randomly assigned to either treatment as usual (with no PS), Basic Body Awareness Therapy or mixed physical activities, subjects in all groups showed similar improvement. As each PS intervention is different, in terms of duration, interdisciplinary model, and PS model, 
it is difficult to compare interventions and to demonstrate which portions of PS interventions are most effective for survivors of torture.

\section{The Center for Victims of Torture (CVT) group PS model}

In the last 10 years, more than 7,000 SoT and other forms of trauma have been treated by CVT PTs in Jordan and Kenya. In Jordan, services are provided at the CVT office in Amman. In this program, $74 \%$ of the patients over the last 3 years have been from either Syria or Iraq, with $21 \%$ from Sudan. In Kenya, CVT provides PS in Nairobi and near the Kakuma refugee camp. In Nairobi, participants attend sessions at one of three urban clinics located in neighborhoods with high refugee populations (Eastleigh, Kayole and Riruta). In Kakuma, the program is located in one of three "villages" (Village 1) in Kalobeyei Integrated Settlement. Kalobeyei is located several kilometers from Kakuma refugee camp and is close to the border between Kenya and South Sudan. There are separate small buildings for counseling and PS services. In both Kenya programs, the biggest population groups have been from the Democratic Republic of the Congo and Burundi. In the Jordan program, there are specialized interventions for children. This article describes only the adult PS program only and the data shared is regarding adult participants. In all program locations, there is simple equipment, such as yoga mats and exercise bands.

PTs perform subjective and objective assessments, including measuring strength, range of movement, posture, gait and body mechanics. In CVT programs that include PS, each participant always receives counseling services as well. The team members collaborate and refer to social work services as needed. CVT's PTs adhere to the principles of the International Organization of PS in Mental Health (IOPTMH). These include providing health promotion, preventive health care, as well as rehabilitation for both individuals and groups (Probst \& Van Damme, 2018).

Although some survivors require individual PS sessions, a majority of CVT patients are seen in groups of between eight and 12. The participants are typically grouped by gender, with the exception of mixed gender LGBTI groups in Nairobi, as well as by country of origin. Each session includes check in and support on goal attainment, exercise, practice of new activities and education about relevant topics. Under the direction of the PT, survivors also support each other in overcoming barriers to goal achievement.

PTs lead discussions and provide psychoeducation about bodily symptoms of trauma, persistent pain and ways to improve sleep. For example, many survivors are not aware that it is important not to drink caffeinated beverages or to exercise heavily soon before going to bed and are able to make changes which enhance their quality of sleep after they receive the education.

PTs utilise a trauma-informed approach in order to avoid retraumatizing participants and to maximize their improvements. PTs offer choices, use invitational language, touch participants only with permission, and respect cultural norms of survivors. Many of those who have undergone torture are hyperaware of bodily sensations. PTs guide survivors to be able to challenge their maladaptive beliefs, as these often contribute to avoiding resumption of activities. In her book, Trauma and Recovery (1992), Judith Herman, a respected pioneer in the field of healing from trauma, describes three stages of recovery. CVT counselors and PTs base some aspects of our treatment models on her work. 


\section{Safety and Stabilization. (Sessions 1,2 and 3)} During this introductory phase, the survivor often feels vulnerable. Providing a safe space to participants is important in this phase. It is crucial to stabilize their physiological and psychological reaction to trauma. Depending on the safety measures in place in the country to which survivors of torture have fled, such as whether or not they have UN-protected status or aspects relating to their socioeconomic status and security of their housing, SoT have various degrees of feeling safe in their overall environments. As needed, CVT counselors and PTs refer survivors to other local or international NGOs and to CVT social workers to address these issues. Providing a sense of safety for those in PS sessions also refers to the importance of having participants agree on principles such as confidentiality and mutual support. In addition, PTs must carefully adhere to principles of traumainformed care. This stage is the starting point. It is necessary for all healing and engagement that follows. In PS group sessions, emphasis is on relaxation and breathing, posture and body mechanics and gentle self-touch. Sleep hygiene discussions and psychoeducation about symptoms of trauma are also typically provided during this stage.

\section{Remembrance and Mourning. (Sessions 4, 5, 6, 7 and 8)}

Once the sense of safety is restored (to the fullest extent possible) and the survivor is stabilized to the extent that the effects of the trauma no longer overwhelm their capacity to function, it is possible to work towards assimilation and integration of the trauma. During the five sessions of this phase, there is an emphasis on pain education and reduction, stretching, strengthening, balance, body mechanics, aerobic exercise and pelvic floor functioning. In all programs, therapeutic pain education is provided for participants that may help them to better identify, localize and decrease their pain. Discussions about pain from a neuroscience perspective are led by the PTs in groups. Survivors often express relief that chronic pain does not mean that an injury has not healed, and that worse pain does not mean worse injury. In addition, they learn that while acute pain has an important protective function, chronic pain no longer has a function. Culturally appropriate metaphors are used (Louw et al., 2019) such as; chronic pain being like a lion in the room, rooster which will not stop crowing, an overly sensitive alarm clock, etc. They are often reassured that despite negative messages which may have been planted by the torturers, they can gradually decrease their pain and improve their overall functional mobility without causing injury to themselves. To reduce any stigma and to normalize the need for education, PTs instruct all group members in techniques such as pelvic floor strengthening and relaxation exercises. The loss of prior physical abilities is acknowledged as is the work of regaining or compensating for their loss. See Figure 1 below for more detail.

\section{Reconnection (Sessions 9 and 10)}

The reconnection stage involves rebuilding one's life and one's future. By being able to overcome feelings of isolation through the reconstruction of meaningful social connections, quality of life is enhanced. Many who are in the reconnection stage of recovery find that they can resume activities, such as playing football, running, playing with their children, taking care of their household needs and resuming livelihood activities.

Each participant is given a packet with pictures of their home exercise program, as well as tips about posture, body mechanics and other key concepts. Participants are re- 
minded that they will have formal follow up sessions with PTs at regular intervals and are encouraged to contact the CVT PS team as needed. There is often a sense of acceptance, that while SoT may not be able to perform the activities in exactly the same manner that

Figure 1. Summary of Activities Carried Out During Each Stage of Trauma Recovery

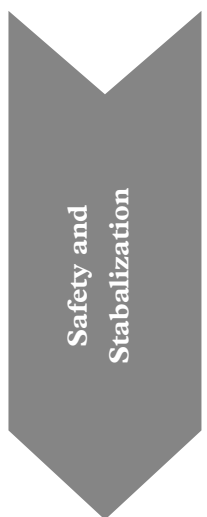

- Safe space for survivors (confidentiality, informed consent, privacy, environmental considerations)

- Establishing trust amongst participants and between participants and physiotherapist

- Explanations of physiotherapy, discussion group norms, expectations of outcomes including specific goals of group members

- Education about trauma and its effects

- Helping survivorss to recognize their feelings and associated physical symptoms

- Teaching techniques for relaxation and managing anxiety

- Teaching self-soothing techniques and body awareness exercises to enable clients to feel more in control and "safe" in their bodies

- Empowering survivors to understand how to safeguard their physical health

- Focus on trauma-informed principles using practices of invitational language, choice, cultural appropriateness of intervention, permission granted before using 'hands-on' approaches

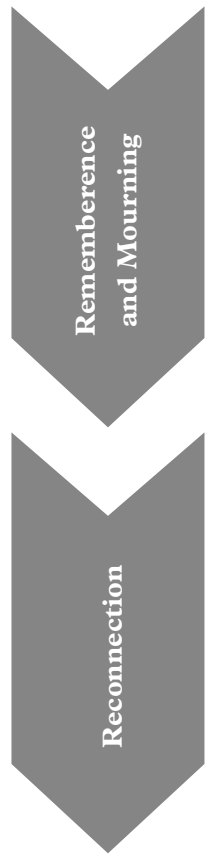

- Managing the physical symptoms of trauma (continuing to identify somatic resources, reinforce relaxation and home exercise programs)

- Decreasing and managing pain (graduated programs, continued reinforcement against maladaptive pain beliefs and behaviors, encouragement and understanding, pacing and coping strategies)

- Restoration of what has been lost where able (strength, range-of-motion, flexibility, balance, coordination, sleep, continence, ability to perfor relevant functional activities)

- Reconnection with one's body through mastery of awareness and self-regulation exercises

- Providing opportunities to practice safe movements that promote joy and renew a sense of confidence in their bodies

- Ongoing self-management of symptoms using goal setting, pacing and increased understanding of symptoms

- Rebuilding positive relationships through contributing to positive group dynamics and safe physical interactions within sessions

- Empowering the individuals to engage with their communities (friends, family, in activities such as sports, livelihood programs, religious events, etc.) 
they could before their torture experiences, they can still enjoy being active and connecting with others.

This stage is focused upon looking to the future and helping participants to utilize their own resources. Herman (1992) suggests that the essence of this stage can be captured by the phrase, "I know I have myself." PS aims to facilitate survivors' reconnection with their own bodies, enabling them to better understand and control their symptoms and to use their bodies as a somatic resource.

\section{Method}

This article presents a secondary analysis of clinical datasets collected by CVT PTs working with survivors in Nairobi, Kakuma, and Jordan.

Participants are recruited into treatment following an initial mental health screening. This screening is conducted by psychosocial counselors to determine general problems and symptoms and if an individual would benefit from, and is interested in, CVT's services. During this process, counselors discuss informed consent. As part of this process, participants can opt-in to their de-identified data being used for research purposes. In Kenya, survivors who have needs in these areas are referred for PS; in Jordan, all survivors are automatically referred for PS.

Part A Disability Rating Index (DRI). Pain-related disability (Harlacher et al., 2016, 2019; Prip et al., 2011) has excellent test-retest reliability (ranging from 0.83 to 0.95 ), strong face validity (with more than $90 \%$ of patients able to answer questions correctly), and strong intra- and inter-rater reliability (0.98 or higher) (Salen et al., 1984). Part B comprises questions on pain, sleep, bladder control, sexual functioning, and body awareness and control using a ten-point scale with 0 anchored to no pain or difficulties, and 10 being the worst imaginable pain or functioning problems. During this assessment participants are asked to describe the parts of their body in which they struggle with pain. Responses are recorded by shading the relevant areas of body outlines (Figure 2). Part C relates to social participation, and part $\mathrm{D}$ includes items on coping and outlook. The entire set of measures has been found to be feasible and acceptable across cultures, has been translated into several languages, and shows strong internal consistency within and across sites (Part A Cronbach's Alphas range from 0.86 to 0.92 ; Part B Cronbach's Alphas range from 0.80 to 0.91 ).

Figure 2. Body outlines used to record pain locations

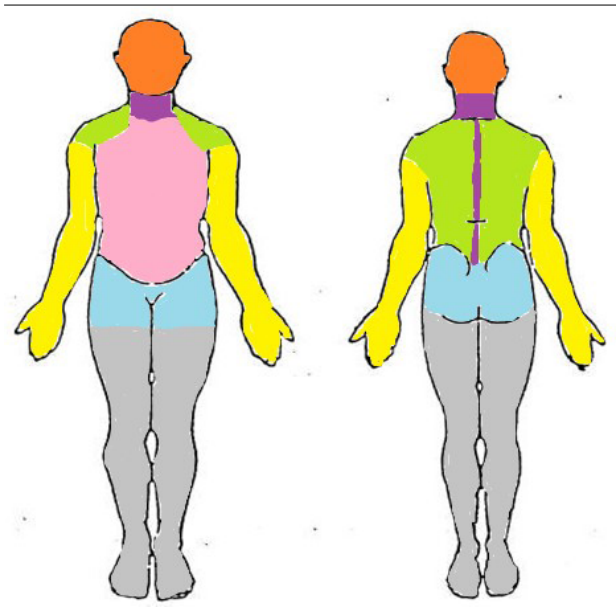

The full PS assessment tool and follow up measures are available from the authors on request.

The assessment is conducted in a private room by a PT. Further verbal consent is sought for physical examination and touch. Assessments are conducted over one or two sessions by PTs familiar with the cultural norms and language needs of the participants; some assessments are administered using trained 
interpreters. The assessment measures perceptions of pain, posture, joint range of motion, strength, nerve involvement, medical history, ruling out "red flag issues" in need of medical attention, and balance. At this time, those with injuries, such as moderate to severe pelvic organ prolapse, anal fissures or severe tears or issues such as gangrene, severe hypertension, pre-eclampsia, breast cancer, and untreated fractures are also referred for medical care.

The "Pelvic Floor Distress Tool"1 (see supplementary materials) was created by the Kenya PS teams to assess and to better address issues with pelvic floor function. This tool has been used on a pilot basis with 130 survivors.

Follow-up assessments are conducted immediately after the PS intervention has been completed as well as at 3- and 9-months from the date of the first treatment session. Only data from the intake and 3-month follow up are included in this paper.

\section{Data Management and Analysis}

Data was recorded on paper forms, reviewed by clinical supervisors, and entered into an encrypted electronic database by monitoring and evaluation staff. Rigorous data protection and confidentiality standards were maintained throughout the process.

Comparison of data is done using Cohen's $\mathrm{d}$ effect sizes, chi-square analyses and repeated measures t-tests.

Table 1 provides breakdowns by gender, country of origin, marital situation, and number of children for each of the three samples, Table 2 provides data on location scheme and area of greatest concern and Table 3 on the number of areas of pain at intake and follow-up.

1 See supplementary materials on https://tidsskrift. $\mathrm{dk} /$ torture-journal/index

\section{Results}

As noted in Table 4 below, $96 \%$ of the combined total of 1183 participants improved in at least one of the four areas of the measure. Table 5 has more detailed statistical analysis of all the areas of the PS assessment tool.

It was hypothesized that survivors of torture would show significantly more improvements in all four sections of the PS assessment tool, as they would have typically endured more trauma than non-survivors. However, only modest differences in rates of improvement, and differences were seen, and only for Parts B and D.

\section{Pelvic floor tool and data}

While only $12.3 \%$ of the participants indicated that they were having issues with pelvic organ prolapse, $16.9 \%$ reported having urinary incontinence at least somewhat, 39.2\% having constipation at times, $29.2 \%$ urinary urgency at least "somewhat." In addition, $20 \%$ of the men and $12.7 \%$ of the women in the pilot indicated having problems with loss of bowel control at least some of the time.

From this initial pelvic floor pilot, there were some troubling findings. For example, $27.9 \%$ of men and $30.9 \%$ of women indicated that they had pain of 4 or more on 1-10 scale during sexual activity (moderate to severe pain). (Please refer to supplemental materials for more results of pelvic floor pilot). Because many participants, both those who report being gender-based violence (GBV) survivors and those who do not, report having concerns about bowel or bladder functioning, PTs have added specific brief teaching modules during the 10-week long individual or group PS cycle. For example, PTs instruct in self -abdominal massage to decrease constipation and provide psychoeducation about toileting posture and foods and beverages, which can make constipation or incontinence. 
To reduce any stigma and to normalize the need for education, PTs instruct all participants in the group in techniques such as pelvic floor strengthening and relaxation exercises. Female genital mutilation (FGM) is very common among some of the patient populations with which CVT works in Kenya (Somalia-98\% estimates, Eritrea, 88\%) FGM survivors have higher rates of both bladder and bowel incontinence than the general population (UNICEF, 2013) which is another reason why it is essential for PTs to address pelvic floor concerns.

\section{Discussion and Conclusions}

This report provides a description of the CVT group PS model for survivors of torture in both urban and refugee camp contexts. The

Table 1. Demographic factors of participants in three program sites

\begin{tabular}{|c|c|c|c|c|}
\hline \multicolumn{2}{|c|}{ Intake Demographics } & \multirow{2}{*}{$\begin{array}{l}\text { Nairobi } \\
(\mathbf{N}=802)\end{array}$} & \multirow{2}{*}{$\begin{array}{l}\text { Jordan } \\
(\mathbf{N}=\mathbf{1 6 3 2})\end{array}$} & \multirow{2}{*}{$\begin{array}{l}\begin{array}{l}\text { Kakuma } \\
(\mathbf{N}=454)\end{array} \\
44 \%\end{array}$} \\
\hline Gender & Men & & & \\
\hline & Women & $59 \%$ & $62 \%$ & $56 \%$ \\
\hline & Non-binary & $1 \%$ & & \\
\hline \multirow[t]{10}{*}{ Country of Origin } & DRC & $45 \%$ & & $31 \%$ \\
\hline & Burundi & $20 \%$ & & $31 \%$ \\
\hline & Somalia & $12 \%$ & $1 \%$ & $0.4 \%$ \\
\hline & South Sudan & $0.2 \%$ & & $18 \%$ \\
\hline & Ethiopia & $7 \%$ & & $16 \%$ \\
\hline & Uganda & $13 \%$ & & $3 \%$ \\
\hline & Syria & & $43 \%$ & \\
\hline & Iraq & & $31 \%$ & \\
\hline & Sudan & & $21 \%$ & \\
\hline & Other & $4 \%$ & $4 \%$ & $1 \%$ \\
\hline \multirow[t]{2}{*}{ Age } & Age range & $13-74$ & $14-82$ & $18-77$ \\
\hline & Age mean & 32 years & 39 years & 36 years \\
\hline \multirow[t]{4}{*}{ Marital Situation } & Married/coupled & $39 \%$ & $69 \%$ & $70 \%$ \\
\hline & Single & $46 \%$ & $19 \%$ & $14 \%$ \\
\hline & Widowed & $9 \%$ & $7 \%$ & $12 \%$ \\
\hline & Divorced/separated & $7 \%$ & $5 \%$ & $4 \%$ \\
\hline \multirow[t]{3}{*}{ Children } & No children & $41 \%$ & $30 \%$ & $16 \%$ \\
\hline & $1-3$ children & $35 \%$ & $38 \%$ & $34 \%$ \\
\hline & $4+$ children & $24 \%$ & $32 \%$ & $50 \%$ \\
\hline $\mathrm{Rx}$ & Taking medications & $32 \%$ & $60 \%$ & $28 \%$ \\
\hline
\end{tabular}


Table 2. Location of Pain and Area of Greatest Concern

\begin{tabular}{|c|c|c|c|}
\hline Areas of Pain at Intake & Nairobi $(\mathrm{N}=802)$ & Jordan $(\mathrm{N}=1619)$ & Kakuma $(N=454)$ \\
\hline Back, shoulders & $610(76 \%)$ & $729(45 \%)$ & $359(79 \%)$ \\
\hline Leg, knee, ankle, foot & $457(57 \%)$ & $988(61 \%)$ & $268(59 \%)$ \\
\hline Chest, abdomen, torso & $385(48 \%)$ & $534(33 \%)$ & $317(70 \%)$ \\
\hline Head, face & $329(41 \%)$ & $599(37 \%)$ & $313(69 \%)$ \\
\hline Neck, spine & $233(29 \%)$ & $745(46 \%)$ & $104(23 \%)$ \\
\hline Arm, wrist, hand & $201(25 \%)$ & $583(36 \%)$ & $132(29 \%)$ \\
\hline Pelvis, hips & $144(18 \%)$ & $324(20 \%)$ & $59(13 \%)$ \\
\hline \multirow[t]{5}{*}{ Area of Greatest Concern } & Nairobi $(\mathrm{N}=782)$ & Jordan $(\mathrm{N}=1583)$ & Kakuma $(\mathrm{N}=443)$ \\
\hline & $\begin{array}{l}\text { Back, shoulders } \\
(47 \%)\end{array}$ & Neck, spine $(23 \%)$ & $\begin{array}{l}\text { Chest, abdomen, } \\
\text { torso }(31 \%)\end{array}$ \\
\hline & $\begin{array}{l}\text { Chest, abdomen, } \\
\text { torso }(14 \%)\end{array}$ & $\begin{array}{l}\text { Leg, knee, ankle, } \\
\text { foot }(22 \%)\end{array}$ & $\begin{array}{l}\text { Back, shoulders } \\
(28 \%)\end{array}$ \\
\hline & $\begin{array}{l}\text { Leg, knee, ankle, } \\
\text { foot }(14 \%)\end{array}$ & $\begin{array}{l}\text { Back, shoulders } \\
(17 \%)\end{array}$ & Head, face $(17 \%)$ \\
\hline & Head, face $(10 \%)$ & Head, face $(14 \%)$ & $\begin{array}{l}\text { Leg, knee, ankle, } \\
\text { foot }(14 \%)\end{array}$ \\
\hline
\end{tabular}

Table 3. Number of areas of pain at intake and three -month follow-up

\begin{tabular}{lllllll}
\hline \multirow{2}{*}{$\begin{array}{l}\text { Number of } \\
\text { areas }\end{array}$} & \multicolumn{2}{c}{ Nairobi $(\mathbf{N}=355)$} & \multicolumn{2}{c}{ Jordan $\mathbf{( N = 6 2 1 )}$} & \multicolumn{2}{c}{ Kakuma (N=192) } \\
\cline { 2 - 7 } & Intake & $\mathbf{3}$ Months & Intake & $\mathbf{3}$ Months & Intake & 3 Months \\
\hline 0 areas & $4(1 \%)$ & $32(9 \%)$ & $6(1 \%)$ & $12(2 \%)$ & $0(0 \%)$ & $24(13 \%)$ \\
\hline 1 area & $53(15 \%)$ & $121(34 \%)$ & $112(18 \%)$ & $217(35 \%)$ & $10(5 \%)$ & $58(30 \%)$ \\
\hline 2 areas & $96(27 \%)$ & $103(29 \%)$ & $174(28 \%)$ & $199(32 \%)$ & $42(22 \%)$ & $58(30 \%)$ \\
\hline $\begin{array}{l}3+\text { areas } \\
\text { Reporting }\end{array}$ & $202(57 \%)$ & $99(28 \%)$ & $329(53 \%)$ & $193(31 \%)$ & 140 & $52(27 \%)$ \\
$\begin{array}{l}\text { fewer areas } \\
\text { at six months }\end{array}$ & & & $329(53 \%)$ & & $156(81 \%)$ & \\
\hline
\end{tabular}

Table 4. Participants who improved in each section of the assessment tool in all three locations and combined

\begin{tabular}{|c|c|c|c|c|c|c|c|c|c|c|c|}
\hline \multirow{3}{*}{$\begin{array}{l}\text { Intake to } \\
\text { 3-month }\end{array}$} & \multirow{3}{*}{$\begin{array}{c}\mathbf{N} \text { (total } \\
\text { participants } \\
\text { assessed) }\end{array}$} & \multicolumn{10}{|c|}{ Participants who improved } \\
\hline & & \multicolumn{2}{|c|}{ A } & \multicolumn{2}{|c|}{ B } & \multicolumn{2}{|c|}{ C } & \multicolumn{2}{|c|}{ D } & \multicolumn{2}{|c|}{$\begin{array}{l}\text { At least } \\
\text { one area }\end{array}$} \\
\hline & & $\mathbf{N}$ & $\%$ & $\mathbf{N}$ & $\%$ & $\mathbf{N}$ & $\%$ & $\mathbf{N}$ & $\%$ & $\mathbf{N}$ & $\%$ \\
\hline Nairobi & 355 & 246 & 69 & 257 & 72 & 200 & 56 & 276 & 78 & 334 & 94 \\
\hline Kakuma & 194 & 168 & 87 & 180 & 93 & 145 & 75 & 172 & 89 & 192 & 99 \\
\hline Jordan & 634 & 424 & 67 & 470 & 74 & 398 & 63 & 441 & 70 & 604 & 95 \\
\hline Combined & 1183 & 838 & 71 & 907 & 77 & 743 & 63 & 889 & 75 & 1130 & 96 \\
\hline
\end{tabular}




\begin{tabular}{|c|c|c|c|c|c|c|c|c|}
\hline Outcome area & Program & $\mathbf{N}$ & $\begin{array}{l}\text { Intake } \\
\text { mean }\end{array}$ & $\begin{array}{l}\text { Intake } \\
\text { SD }\end{array}$ & $\begin{array}{l}\text { 3- month } \\
\text { mean }\end{array}$ & $\begin{array}{l}\text { 3- month } \\
\text { SD }\end{array}$ & $\begin{array}{l}\text { Cohen's } \\
\text { d }\end{array}$ & $\mathbf{p}$ \\
\hline \multirow{3}{*}{$\begin{array}{l}\text { Part A: } \\
\text { Functional ability } \\
\text { (12 items) } \\
0=\text { without difficulty } \\
\text { / } 100=\text { cannot do ac- } \\
\text { tivity at all }\end{array}$} & Jordan & 634 & 38.3 & 21.1 & 29.4 & 19.3 & 0.439 & $\star \star \star$ \\
\hline & Nairobi & 356 & 36.5 & 19.5 & 27.6 & 21.0 & 0.442 & $\star \star \star$ \\
\hline & Kakuma & 194 & 35.8 & 21.0 & 13.6 & 15.5 & 1.202 & $\star \star \star$ \\
\hline \multirow{3}{*}{$\begin{array}{l}\text { Part B: } \\
\text { Body functions } \\
\& \text { physicality ( } 11 \\
\text { items) } \\
0=\text { no pain; excellent / } \\
10=\text { worst pain; poor }\end{array}$} & Jordan & 638 & 4.6 & 1.6 & 3.3 & 1.6 & 0.827 & $\star \star \star$ \\
\hline & Nairobi & 355 & 3.7 & 1.7 & 2.7 & 1.9 & 0.571 & $\star \star \star$ \\
\hline & Kakuma & 194 & 4.2 & 1.7 & 1.4 & 1.4 & 1.830 & $\star \star \star$ \\
\hline \multirow{3}{*}{$\begin{array}{l}\text { Part C: } \\
\text { Social participation } \\
\& \text { functioning ( } 8 \\
\text { items) } \\
1=\text { worst outcome / } 4 \\
=\text { best outcome }\end{array}$} & Jordan & 638 & 2.8 & 0.6 & 3.0 & 0.6 & 0.453 & $\star \star \star$ \\
\hline & Nairobi & 355 & 2.8 & 0.6 & 3.0 & 0.7 & 0.265 & $\star \star \star$ \\
\hline & Kakuma & 194 & 2.9 & 0.5 & 3.3 & 0.4 & 0.896 & $\star \star \star$ \\
\hline \multirow{3}{*}{$\begin{array}{l}\text { Part D: } \\
\text { Coping \& outlook } \\
(11 \text { items }) \\
1=\text { worst outcome / } 4 \\
=\text { best outcome }\end{array}$} & Jordan & 638 & 2.7 & 0.3 & 2.9 & 0.3 & 0.699 & $\star \star \star$ \\
\hline & Nairobi & 355 & 2.6 & 0.4 & 3.0 & 0.4 & 0.948 & $\star \star \star$ \\
\hline & Kakuma & 194 & 2.6 & 0.4 & 3.1 & 0.3 & 1.487 & $\star \star \star$ \\
\hline
\end{tabular}

quantitative results presented above are supported by anecdotal feedback to CVT's PTs.

Before attending PS sessions, I was not able to attend community meetings, but now I attend them and have also joined a tailoring class. Now, I feel much more hopeful about my future and about the possibility of earning income! (40-year-old male survivor)
I could not do most of my daily activities like fetching water, or sweeping, and would rely on my neighbors, but now I am able to carry a 10- liter container of water. Before attending PS sessions, I could not stand upright because of my back pain, but now I have no back pain, and I do my exercises every day. (62-year-old female survivor) 
Table 6. Number of participants showing improvement between baseline and three-month follow up in Jordan, Nairobi, and Kakuma

\begin{tabular}{|c|c|c|c|c|}
\hline & $\begin{array}{l}\text { Survivors of } \\
\text { torture }\end{array}$ & $\begin{array}{l}\text { No reported } \\
\text { torture }\end{array}$ & Total & $\begin{array}{l}\text { Total } \\
\text { number of } \\
\text { participants } \\
\text { assessed (N) }\end{array}$ \\
\hline $\begin{array}{l}\text { Part A: } \\
\text { Functional ability }\end{array}$ & $361(74.0 \%)$ & $476(68.8 \%)$ & $837(70.9 \%)$ & 1180 \\
\hline $\begin{array}{l}\text { Part B: } \\
\text { Body functions \& } \\
\text { physicality }\end{array}$ & $399(81.6 \%)$ & $506(72.9 \%)$ & 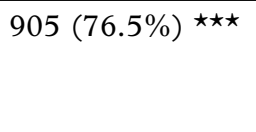 & 1183 \\
\hline $\begin{array}{l}\text { Part C: } \\
\text { Social participation } \\
\text { \& functioning }\end{array}$ & $309(63.2 \%)$ & $433(62.4 \%)$ & $742(62.7 \%)$ & 1183 \\
\hline $\begin{array}{l}\text { Part D: } \\
\text { Coping \& outlook }\end{array}$ & $393(80.4 \%)$ & $495(71.3 \%)$ & 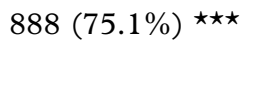 & 1183 \\
\hline $\begin{array}{l}\text { P-value (two-tailed) from } \\
{ }^{\star} \mathrm{p} \leq 0.05 \\
{ }_{\star \star} \mathrm{p} \leq 0.01 \\
{ }_{\star \star \star} \mathrm{p} \leq 0.001\end{array}$ & hi-square tests o & nificance & & \\
\hline
\end{tabular}

Similarly, survivors noting improvement in pelvic floor functioning describe a renewed desire to be sexually active with their partners, as well as being able to relax and having less pain. They also report being able to resume attendance at religious activities and other community events as they are confident that they will no longer have leaking of their bladder or bowels with resultant odor, and that they are able to walk longer distances in the community without worrying about embarrassing bowel or bladder accidents on the way.

Several limitations must be considered when reviewing these findings. Firstly, these preliminary results are presented without comparison to a control group. The contribution of non-specific therapeutic factors such as a strong therapeutic alliance, group support and structured assessment are well documented. Secondly, since CVT's approach includes both counselling and PS intervention, we are unable in this analysis to separate out those benefits resulting from different aspects of our interdisciplinary work. Thirdly, although the sample sizes presented here are large, they represent only a small part of the total set of survivors who received treatment in the Kenya program, and a majority of those receiving services in the Jordan program.

In humanitarian settings with great need and limited resources, and in places where survivors are often moving around, long-term follow up is challenging. As a result, we have no data on the functioning of those with whom we have lost contact following the end of treatment. Finally, we also lack data on those who 
dropped out of treatment before the end of the program. Given these significant limitations, the authors merely note the overall benefits in quality of life and functioning to those participants with whom we are have seen for follow up assessments, and make no claims to specific therapeutic mechanism or comparative treatment efficacy. We point to the important complimentary role that PS can play in interdisciplinary care. In closing, we call for more research into the efficacy of group PS interventions with survivors of torture, especially those living in low and middle-income countries, and note the importance of issues relating to the pelvic floor in working with survivors of torture.

\section{Supplemental material (available at https:// tidsskrift.dk/torture-journal) :}

\section{Copy of the Pelvic Floor Distress Inventory Tool}

2. Additional data which was not shared in the body of the article about changes between baseline and 3-month follow-up assessments

\section{References}

Amris, K., Jones, L. E., \& Williams, A. C. (2019). Pain from torture: Assessment and management. Pain Reports, 4(6), e794. https://doi.org/10.1097/ PR9.0000000000000794

Andrews, N. E., Strong, J., Meredith, P. J., \& D'Arrigo, R. G. (2014). Association between physical activity and sleep in adults with chronic pain: A momentary within person perspective. Physical Therapy, 94(4), 499-510.

Andersen, T. E., Ellegaard, H., Schiottz-Christensen, B., Mejldal, A., \& Manniche, C. (2020). Somatic Experiencing ${ }^{\circledR}$ for patients with low back pain and comorbid posttraumatic stress symptoms-a randomised controlled trial. European fournal of Traumatology, 11(1), https://doi.org/10.1080/2000 8198.2020.1797306

Baird, E., Williams, A. C., Hearn, L., \& Amris, K. (2017) Interventions for treating persistent pain in survivors of torture. Cochrane Database Systems
Review, 8(8), https://doi.org/10.1002/14651858. CD012051.pub2

Buczynski, R., van der Kolk, B., Ogden, P., Levine, P., \& Lanius, R. (2018). Treating trauma master series: How to work with the limbic system to reverse the physiological imprint of trauma. NICABM, 5, 1-29.

Bunn, M., Goesel, C., Kinet, M., \& Ray, F. (2015). Group treatment for survivors of torture and severe violence: A literature review. Torture 26(1), 45-67. https://doi.org/10.7146/torture. v27i1.108062

Crosby, S. S. (2013). Primary care management of non-English speaking refugees who have experienced trauma: A clinical review. Fournal of the American Medical Association, 310(5), 519-528.

de Ruiter, M., Gamble, A., Gueron, L. P., Kibet, J. J., \& O'Reilly, C. (2018). Physiotherapy with survivors of torture and trauma. In M. Probst \& L.H. Skjaerven (Eds.) Physiotherapy in Mental Health and Psyhiatry: $A$ Scientific and Clinical Based Approach (pp. 206-225). Edinburgh: Elsevier.

Dibaj, I., Halvorsen, J. O., Kennair, L. E.O., \& Stenmark, H. I. (2017). An evaluation of combined narrative exposure therapy and physiotherapy for comorbid PTSD and chronic pain in torture survivors. Torture, 27(1), 13-27. https://doi.org/10.7146/torture. v27i1.26534

Gard, G., \& Gyllensten, A. L. (2018). Musculoskeletal pain: Evidence and critical factors in rehabilitation relevant for physiotherapy in mental health. In M. Probst \& L.H. Skjaerven (Eds.) Physiotherapy in Mental Health and Psyhiatry: A Scientific and Clinical Based Approach (pp. 134-140). Edinburgh: Elsevier

Harlacher, U., Nordin, L., \& Polatin, P. (2016). Torture survivors' symptom load compared to chronic pain and psychiatric in-patients. Torture, 26(2), 74-84

Harlacher, U., Polatin, P., Taing, S., Phana, P., Sok., P., \& Sothera, C. (2019). Education as a treatment for chronic pain in survivors of trauma in Cambodia: Results of a randomized controlled outcome trial. International fournal of Conflict and Violence, 13, 1-26. doi: 10.4119/ijcv-3124

Herman, Judith. (1992). Trauma and Recovery: The Aftermath of Violence-From Domestic Abuse to Political Terror. New York, NY: Basic Books.

Jones, F., \& Kulnik, S. T. (2018). Self-management. In S. Lennon, G. Ramdharry, \& G. Verheyden (Eds.), Physical Management for Neurological Conditions, 3rd ed., (pp. 379-396). Edinburgh: Elsevier Churchill Livingstone 
Kaur, G., Weinberg, R., Milewski, A. R., Huynh, S., Mauer, E., Hemmings Jr., H. C., \& Pryor, K. O. (2020). Chronic pain diagnosis in refugee torture survivors: A prospective, blinded diagnostic accuracy study. Fournal of Physical Medicine and Rehabilitation. 17(6), e1003108. https://doi. org/10.1371/journal.pmed.1003108

Knapen, J., Morien, Y., \& Marchal, Y. (2018). Physiotherapy for patients with depression. In M. Probst \& L.H. Skjaerven (Eds.) Physiotherapy in Mental Health and Psyhiatry: A Scientific and Clinical Based Approach (pp. 253-257). Edinburgh: Elsevier

Louw, A., Puentedura, E.L., Diener, I., Zimney, K., \& Cox, T. (2019). Pain neuroscience education: Which pain neuroscience education metaphor worked best? South African fournal of Physiotherapy, 75(1). https://doi.org/10.4102/sajp. v75i1.1329,

Louw, A., Zimney, K., Puentedura, E. J., \& Diener, I. (2016). The efficacy of therapeutic neuroscience education on musculoskeletal pain: A systemic review of the literature. Physiotherapy Theory and Practice, 32(5), 332-355. https://doi.org/10.1080/0 9593985.2016.1194646

Nielsen, H. F. (2014). Interventions for physiotherapists working with torture survivors, with special focus on traumatic pain, PTSD, sleep issues. Dignity Publication Series on Torture and Organized Violence-Praxis Paper, No. 6, 1-82. Copenhagen, Denmark.

Nordbrandt, M. S., Sonne, C., Mortensen, E. L., \& Carlsson, J. (2020). Trauma-affected refugees treated with basic body awareness therapy or mixed physical activity as augmentation to treatment as usual-A pragmatic randomised controlled trial. PLos One, 15(3), e0230300. https://doi.org/10.1371/journal.pone. 0230300

Nordin, 1., \& Perrin, S. (2019). Pain and posttraumatic stress disorder in refugees who survived torture: The role of pain catastrophizing and trauma-related beliefs. European fournal of Pain, 23, 1497-1506. https://doi.org/10.1002/ ejp. 1415

O'Keeffe, M., Hayes, A., McCreesh, K., Purtill, H., \& O'Sullivan, K. (2017). Are group-based and individual physiotherapy exercise programmes equally effective for musculoskeletal conditions? A systematic review and meta-analaysis. British fournal of Sports Medicine, 51(2), 126-132. https://doi.org/10.1136/bjsports-2015-095410

Olsen, D., Montgomery, E., Carlsson, J., \& Foldspang, S. (2007). Prevalence of pain in the head, back and feet in refugees previously exposed to torture: A ten year follow up study.
Disability and Rehabilitation, 29(2), 163-171. https://doi.org/10.1080/09638280600747645

O’Sullivan, V. (2015). Releasing the pain: Physiotherapy with victims of torture and trauma. Refugee Transitions, Publications of STARTTS (NSW Service for the treatment and rehabilitation of torture and trauma survivors), 30, 31-37.

Persson, A. L., Veenhuizen, H., Zachrison, L., \& Gard, G. (2008). Relaxation as treatment for chronic musculoskeletal pain: A systematic review of randomised controlled studies. Physical Therapy Reviews, 13(5), 355-365. https:/doi. org/10.1179/174348808X356366

Price, C. J., \& Hooven, C. (2018). Interoceptive awareness skills for emotional regulation: Theory and approach of mindful awareness in Body-Oriented Therapy (MABT). Frontiers in Psychology, 9(798), published online 2018 May 28. https://doi.org/10.3389/fpsyg.2018.00798

Prip, K., Persson, A. L., \& Sjolund, B. H. (2011). Self-reported activity in tortured refugees with long-term sequelae including pain and the impact of foot pain from falanga: A cross-sectional study. Disability and Rehabilitation, 33(7), 569-578. https://doi.org/10.3109/09638288.2010.493597

Probst, M., Van Damme, T., \& Vancampfort, D. (2018). Psychomotor therapy or physiotherapy in mental health for patients with psychiatric problems. In M. Probst \& L.H. Skjaerven (Eds.) Physiotherapy in Mental Health and Psyhiatry: A Scientific and Clinical Based Approach (pp. 69-73). Edinburgh: Elsevier

Rosenberg, T.Y. (2007). Pelvic floor involvement in male and female sexual dysfunction and the role of pelvic floor rehabilitation in treatment: A literature review. The fournal of Sexual Medicine, 41(1),3-13. https://doi.org/10.1111/j.17436109.2006.00393.x

Rossettini, G., Camerone, E. M., Carlino, E., Benedetti, F., \& Testa, M. (2020). Context matters: The psychoneurobiological determinants of placebo, nocebo and context-related effects in physiotherapy. Archives of Physiotherapy, 10(11). https://doi.org/10.1186/s40945-020-0082-y

Salen, B.A., Spangfort, E.V., Nygren, A.L., \& Nordemer, R. (1984). The Disability Rating Index: An instrument for the assessment of disability in clinical settings. Fournal of Clinical Epidemiology, 47(12), 1423-1435. https://doi. org/10.1016/0895-4356(94)90086-8

Sallinen, M. (2018). Physiotherapy interventions in individuals with chronic widespread pain or chronic fatigue syndrome. In M. Probst \& L.H. Skjaerven (Eds.) Physiotherapy in Mental Health 
and Psyhiatry: A Scientific and Clinical Based Approach (pp. 167-173). Edinburgh: Elsevier

Sandahl, H., Jennum, P., Baandrup., L., Poschmann, I.S., \& Carlsson, J. (2017). Treatment of sleep disturbances in trauma-affected refugees: Study protocol for a randomised controlled trial. Trials, 18(1):520. https://doi.org/10.1186/s13063-0172260-5

Saragiotto, B. T., de Almeida, M. O., Yahato, T. P., \& Maher, C. G. (2016). Multidisciplinary biopsychosocial rehabilitation for nonspecific chronic low back pain. Physical Therapy, 96(6), 759-763. https://doi.org/10.2522/ptj.20150359

Siengsukon, C. F., Al-dughmi, M., \& Stevens, S. (2017). Sleep health promotion: Practical information for physical therapists. Physical Therapy, 97(8), 826-836. https://doi.org/10.1093/ ptj/pzx057

Skjaerven, L.H., Parker, A.R., \& Mattsson, M. (2018). Group therapeutic factors for use in physiotherapy in mental health: A core in group physiotherapy. In M. Probst \& L.H. Skjaerven (Eds): Physiotherapy in Mental Health and Psyhiatry: A Scientific and Clinical Based Approach, [pp. 92-96). Edinburgh: Elsevier.

Stammel, N., Knaevelsrud, C., Schock, K., Walther, L.C. S., Wenk-Ansohm, M. P., \& Bottche, M. (2017). Multidisciplinary treatment for traumatized refugees in a naturalistic setting: Symptom courses and predictors. European fournal of Psychotraumatology. 8(2), 1-13. https:// doi.org/10.1080/20008198.2017.1377552

Tsur, N., Defrin, R., Shahar, G., \& Solomon, Z. (2020). Dysfunctional pain perception and modulation among torture survivors: The role of pain personification. Fournal of Affective Disorders, 15(265). 10-17. https://doi.org/10.1016/j. jad.2020.01.031

United Nations Convention Against Torture, article 27(1), 1984, New York, NY.

UN General Assembly, Convention Against Torture and Other Cruel, Inhuman or Degrading Treatment or Punishment, 10 December 1984, United Nations, Treaty Series, vol. 1465, p. 85

UNICEF, Statistics and Monitoring Section (2013). Female genital mutilation/Cutting: A statistical overview and exploration of the dynamics of changes. New York, New York.

Van Damme, T. (2018). Relaxation therapy. In M. Probst \& L.H. Skjaerven (Eds.) Physiotherapy in Mental Health and Psyhiatry: A Scientific and Clinical Based Approach (pp. 80-85): Edinburgh: Elsevier

Vancampfort, D., \& Stubbs, B. (2018). Improving adherence to physiotherapy in mental health settings: The need for autonomy, competence and social relatedness. In M. Probst \& L.H. Skjaerven (Eds.) Physiotherapy in Mental Health and Psyhiatry: A Scientific and Clinical Based Approach (pp. 32-35). Edinburgh: Elsevier

Walker, J., \& Shepherd, W. (2001). Anxiety disorders: A nation-wide survey of treatment approaches used by physiotherapists. Physiotherapy, 87(10), 536-548. https://doi.org/10.1016/S00319406(05)65452-1

Wang, S., Bytyci, A., Izeti, S., Kallaba, M., Rushiti, R., Montgomery, E., \& Modvig, J. (2016). A novel bio-psycho-social approach for rehabilitation of traumatized victims of torture and war in the post-conflict context: A pilot randomized controlled trial in Kosovo. Conflict and Health, 10(34). https://oi.org/10.1186/ s13031-016-0100-y

Williams, A. C., \& Baird, E. (2016). Special considerations for the treatment of pain from torture and war. Current Anesthesiology Reports, 6(4). 319-326. https://doi.org/10.1007/s40140016-0187-0

Wood, L., \& Hendrick, P. A. (2019). A systematic review and meta-analysis of pain neuroscience education for chronic low back pain: Shortand long-term outcomes of pain and disability. European fournal of Pain, 23(2), 234-249. https:// doi.org/10.1002/ejp.1314

\section{Acknowledgements}

To the many physiotherapists working with CVT in Jordan, Nairobi and Kakuma who are not named in this article who work with survivors every day, to Craig Higson-Smith, Shannon Golden and Raghda Elshafie from the CVT research department, who helped greatly with this article, and especially to survivors of torture and other forms of trauma, from whom we learn so much. Special thanks to MaryAnn de Ruiter, the first staff physiotherapist from CVT, who helped to create the physiotherapy assessment tool and to pioneer integration of physiotherapy for CVT participants, and to Ilona Fricker and Claire O'Reilly, who created the CVT ten -session group physiotherapy model. 


\section{Funding}

The Center for Victims of Torture provided partial funding for the writing of this article. PRM (Bureau of Population, Refugees, and Migration, United States Department of State is the largest funder of Center for Victims of Torture programs in Kenya and Jordan. 